\title{
As imagens no jornalismo de guerra e o Pathosformel: os painéis de Warburg como método de construção de conhecimento
}

Lucia Leão'

http://orcid.org/0000-0002-6680-5106

\section{Luma Santos de Oliveira'}

https://orcid.org/0000-0002-4538-7398

I - Pontifícia Universidade Católica de São Paulo. São Paulo (SP), Brasil.

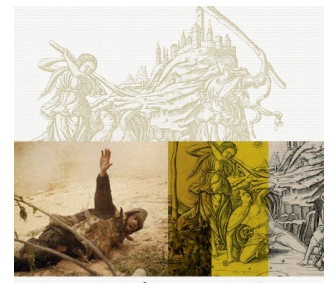

LEÃo SERVA A FÓRMULA DA EMOÇ̄̃̃o HA FOTOGRGFIA DE GLEREA
SERVA, L.

A fórmula da emoção na fotografia de guerra. São Paulo: Edições Sesc São Paulo, 2020. 204p.

Resumo: Acompanhando o jornalismo de guerra desde o seu princípio, a fotografia que registra tais episódios é marcada por uma bagagem imagética que se vale de fórmulas particulares para expressar diferentes emoções. Em seu livro, Leão Serva evidencia os caminhos através dos quais as imagens 
estabelecem tal método em nossa cultura, recorrendo sobretudo ao legado das pesquisas de Aby Warburg. O autor se baseia no Atlas Mnemosine de Warburg para criar seus próprios painéis, apontando as especificidades das fotografias de guerra e de que forma estão empregadas nelas as fórmulas da emoção, ou Pathosformeln. A obra de Serva é notável ao revelar como o processo de criação fotográfico dialoga com esses padrões e como a utilização dos painéis pode contribuir na construção do conhecimento sobre o imaginário.

Palavras-chave: imagem; imaginário; fotojornalismo; Aby Warburg; guerra.

\begin{abstract}
Images in war journalism and Pathosformel: Warburg's panels as a method of building knowledge - Following war journalism since its inception, the photography that records such episodes is marked by an imagery baggage that uses particular formulas to express different emotions. In his book, Leão Serva highlights the ways in which images establish such a method in our culture, drawing above all on the legacy of Aby Warburg's research. The author draws on Warburg's Atlas Mnemosyne to create his own panels, pointing out the specifics of war photographs and how the formulas of emotion, or Pathosformeln, are used in them. Serva's work is remarkable in revealing how the process of photographic creation dialogues with these standards and how the use of panels can contribute to the construction of knowledge about the imaginary.
\end{abstract}

Keywords: image; imaginary; photojournalism; Aby Warburg; war.

O atlas é uma forma visual do saber, uma forma sábia de ver.

Didi-Huberman (2018, p.18)

\title{
0 método
}

A crescente produção e circulação de imagens, que atuam nos processos comunicacionais cotidianos, é um fenômeno complexo que requer métodos de investigação condizentes com suas multiplicidades e heterogeneidades. As dificuldades que acompanham essas pesquisas vão desde a questão do enorme volume de dados à escolha de instrumentos e métodos de análises. No caso de estudos sobre as imagens e imaginários, os sistemas de organização e classificação fixos e cristalizados das abordagens clássicas constituem os principais obstáculos. Mais do que nunca, a adoção de práticas investigativas criativas que favoreçam experimentações e mobilizações do pensamento podem contribuir para a descoberta de significados profundos latentes.

Neste contexto, A fórmula da emoção na fotografia de guerra (2020), livro de Leão Serva, é uma contribuição original e valiosa. Fruto de sua tese de 
doutorado em Comunicação e Semiótica na PUC-SP, com orientação de Norval Baitello, o livro se fundamenta no pensamento de Aby Warburg (1856-1929), sendo um convite para conhecer as potências heurísticas do projeto Atlas Mnemosyne no estudo das imagens de guerra. Desenvolvido a partir do questionamento "o que nas imagens de guerra atrai a atenção dos espectadores?", o pensamento de Serva aborda tópicos como memória cultural da humanidade e persistência de imagens de diferentes épocas e lugares que são reconhecíveis universalmente. Entre a discussão de diversas questões relativas à importância do estudo das imagens na cultura, o autor visa demonstrar como a fotografia de guerra contém aquilo que Warburg denominou como fórmula de emoção.

No livro, o belíssimo projeto gráfico elaborado por Victor Burton dialoga de forma enriquecedora com o texto, favorecendo a compreensão das dinâmicas entre as imagens. Já na capa, é possível contemplar uma composição que mescla o gesto de um braço levantado na fotografia do brasileiro André Liohn, que retrata um rebelde líbio ferido em 2011, e o mesmo gesto na gravura em cobre do círculo de Andrea Mantegna (1470-80). É digno de nota observar que Liohn recebeu o prestigiado prêmio Robert Capa por suas fotografias da guerra civil na Líbia. A composição da capa nos convida a pensar sobre a universalidade de um gesto que ultrapassa as fronteiras de tempo e espaço. Não por acaso, essas duas imagens carregam a mesma gestualidade presente no desenho à bico de pena de Albrecht Dürer (1494) sobre o episódio da Morte de Orfeu estudada por Warburg e que desvela uma reação universal diante de uma ameaça de morte. No artigo Dürer e a antiguidade italiana, Warburg (2015) desenvolve um vasto estudo iconográfico sobre a presença dessa gestualidade, que inclui, com "o acento enfático da Morte de Orfeu", imagens pintadas em vasos gregos e outras imagens em pratos e livros. Ao discorrer sobre essa "coreografia trágica", Warburg afirma que essas imagens incorporam na "[...] descrição da vida em movimento as fórmulas genuinamente antigas para expressões exacerbadas no corpo ou da alma" (WARBURG, 2015, p. 91).

Entre as inúmeras contribuições de Warburg para o campo da pesquisa em ciências da comunicação e da ciência da cultura, a noção de pós-vida das imagens (Nachleben) e o conceito de Pathosformel (no plural Pathosformeln), ou fórmula de pathos (emoção), se destacam como fundamentos para um modo de pensar por imagens. Antes de avançarmos sobre a discussão de como Leão Serva se fundamenta nos conceitos de Warburg para o desenvolvimento de sua tese, faz-se necessário apresentar algumas ponderações. 
Comecemos com a noção de cultura. Segundo Carlo Ginzburg, Warburg compreende a cultura como "[...] uma espécie de entidade unitária composta por arte, literatura, filosofia e ciência, mas também por superstições a atividades manuais." (GINZBURG, 1999, p. 48)1. Neste sentido, é importante ter em mente que as experimentações com imagens de Warburg estão diretamente ligadas a um processo que visa ampliar o conhecimento sobre a cultura. Já o conceito de imagem, em Warburg, implica um entendimento que vai muito além da representação visual, visto que, segundo sua abordagem, as imagens permitem desenvolver pensamentos complexos sobre conteúdos enigmáticos, dolorosos ou mesmo desconhecidos.

Sobre a noção de pós-vida das imagens, Baitello (2010) nos oferece uma síntese iluminadora ao analisar as pesquisas de Warburg sobre analogias imagéticas entre a cultura dos índios Pueblo na América do Norte e a Antiguidade Pagã Europeia. No caso, Warburg estava se referindo à persistência da imagem da serpente em culturas distantes, tanto em termos cronológicos como espaciais (WARBURG, 2015, p. 199-288). Segundo Baitello, a presença de uma pós-vida (Nachleben) nos símbolos evoca:

[...] algo como um cerne arcaico que sobrevive na cultura, como um fundamento da memória, contudo sempre ambivalente ou dicotomizado, esquizoide, oscilando em diferentes épocas entre universos de formas antípodas. A cultura se constitui, portanto, como um campo de permanente conflito de tensões e jamais uma sucessão ou um fluir de momentos [...] (BAITELLO, 2010, p. 76).

Ancorado em uma lógica combinatória e adotando procedimentos típicos daquilo que atualmente denomina-se sistemas abertos (open systems), os Pathosformeln são dispositivos móveis e abertos à experimentação, visto que são pensados para permitir múltiplas configurações. Como veremos, as fórmulas de emoção irão compor a base para a experimentação com imagens de guerra que Serva brilhantemente nos oferece em seu livro.

\section{O livro}

O criterioso olhar de Leão Serva sobre as fotografias de guerra, categoria que surge no meio jornalístico em meados do século XIX, aponta para o reconhecimento de padrões no registro de diferentes cenas que buscam retratar as situações vividas nas batalhas (SERVA, 2020). Ao explorar esses 
padrões de semelhança, Serva toma como base o conceito de Pathosformel, mostrando como as fórmulas da emoção carregam a herança de representações imagéticas da antiguidade, sendo reproduzidas até hoje como método de despertar as mesmas agitações passionais.

Estruturado em seis blocos, o livro inicia apresentando o problema da pesquisa, metodologia e corpus, discorrendo sobre o conceito de fórmula da emoção. No segundo capítulo, Serva traça um panorama sobre a fotografia de guerra no decorrer da história e suas relações com o jornalismo. Warburg e seus estudos é o tema do terceiro bloco, que compreende uma discussão aprofundada sobre as principais influências warburguianas e também apontamentos sobre os arquivos de guerra e o projeto Atlas. Em seguida, Serva apresenta estudos sobre temas culturais contemporâneos desenvolvidos por autores que se inspiraram em Warburg. Já nesta parte do livro, Serva nos apresenta um dos painéis que elaborou aplicando os procedimentos da fórmula da emoção. Em diálogo com o estudo de Ginzburg Seu país precisa de você (1999), o autor desenvolve um painel (Painel A: Dedo de Deus) sobre o motivo do dedo em riste, uma fórmula da emoção. Em sua composição, Serva reúne um cartaz de propaganda inglesa da I Guerra Mundial, um outro similar do Brasil, convocando pessoas para a Revolução de 1932 e imagens de políticos brasileiros atuais que exibem o gesto do dedo em riste. Na rica análise de Serva, podemos perceber as profundas conexões presentes nas gestualidades de diferentes períodos e locais. Os capítulos seguintes se desdobram a partir da ideia de Pathosformel na fotografia de guerra e correspondem à aplicação do método warburguiano na elaboração de dez painéis.

Conforme expõe Serva, citando o clássico livro da história do jornalismo de guerra de Phillip Knightley, The First Casualty (2003), a fotografia se une ao jornalismo de guerra já na cobertura da Guerra da Criméia, durante a primeira metade da década de 1850, com o trabalho realizado pelos britânicos William Howard Russel, repórter, e o fotógrafo Roger Fenton. O autor informa ainda que a cobertura jornalística com fotografias da guerra causavam grande impacto, aumentando a influência, circulação e lucro dos jornais. O desenvolvimento tecnológico da fotografia acompanha a demanda das coberturas de guerra e, com o passar do tempo, as câmeras se tornam cada vez mais portáteis e as imagens mais fáceis de serem reproduzidas. Em paralelo a este movimento, as fotografias contribuíram no estabelecimento de profissionais que se tornaram referência para a fotografia de modo geral. 
No capítulo dedicado a Aby Warburg, Serva discorre sobre as conexões entre sua história pessoal e os variados estudos que desenvolveu. Warburg abdica da função de comandar os negócios financeiros da família para se dedicar aos estudos da arte, vendendo ao irmão sua primogenitura em troca da compra de todos os livros que ele tivesse interesse em adquirir durante sua vida, o que foi cumprido e deu origem ao Instituto Warburg. Interdisciplinar e global, vinculado à Escola de Estudos Avançados da Universidade de Londres, na Inglaterra, o Instituto Warburg tem como objetivo fomentar pesquisas sobre história da cultura e o papel das imagens na cultura. É importante observar que Serva desenvolveu parte de sua pesquisa no Instituto Warburg, em viagem realizada graças à Bolsa da CAPES. Segundo o autor, as pesquisas de Warburg são marcadas por grande interesse na presença de imagens da época pagã durante o Renascimento italiano; além disso, é notório também a influência dos trabalhos de Darwin que abordavam as expressões humanas presentes no livro publicado originalmente em 1872, A expressão das emoções no homem e nos animais (DARWIN, 2013).

Em sua tese de doutorado O nascimento de Vênus e A primavera de Sandro Botticelli, originalmente publicada em 1892, Warburg (2013) já discute questões que permeiam toda sua pesquisa, a presença da antiguidade clássica na arte do Renascimento e a expressão do movimento. Durante seus estudos acerca do Renascimento, mais precisamente a respeito de um desenho de Dürer sobre a morte de Orfeu, Warburg percebe a semelhança do gesto retratado com outra gravura do mesmo período que remetia, ainda, a uma obra da antiguidade, que expressa um sentimento de terror e emoção, podendo ser reconhecida imediatamente pelo observador. Essa padronização de gestos para representar uma emoção foi chamada por Warburg de Pathosformel, traduzida como fórmula de pathos - compreendendo como fórmula de paixão ou fórmula da emoção — sendo esta última a maneira que Serva (2020) prefere adotar em suas abordagens. Ele também frisa que outro conceito que aparece constantemente nos estudos de Warburg é o de Nachleben, para tratar a pós-vida de imagens da antiguidade clássica presentes no Renascimento, ou sua "vitalidade continuada", conforme escolhe interpretar Gombrich (1992).

Os estudos de Warburg, segundo Serva (2020), culminam na construção de um conjunto de painéis com imagens móveis que foi nomeado de Atlas Mnemosine, uma referência à deusa grega da Memória, mãe das Musas. Nesses painéis, Warburg exercita sua arte de aproximação que nos conduz 
a buscar sentidos concatenando elementos gestuais expressivos e contrapondo diferenças e semelhanças. Em sua proposta criativa, Serva adota esse mesmo procedimento e desenvolve dez painéis com foco em fotografias de guerra: no painel 1, o tema é a expressão do movimento; no painel 2, explora os gestos na pintura e na fotografia de guerra; no 3, rostos; no 4, o motivo dos decapitados; no 5, caveiras; no 6, crucificação; no painel 7, o tema da descida da cruz; no 8, pessoas vivas em chamas; no 9, massacre dos inocentes; e finalmente, no painel 10, os fuzilados.

\section{Os painéis de Serva}

O primeiro painel aborda a expressão do movimento e agrega imagens como uma pintura rupestre do parque nacional da Serra da Capivara (Piauí, Brasil); uma ilustração do mito de Perseu presente em um manuscrito da Holanda do século IX; uma fotografia da II Guerra Mundial; e a pintura intitulada O nascimento de Vênus de Sandro Botticelli, obra presente nos estudos de Warburg, entre outras. Na análise sobre esse tema, Serva discorre sobre a importância da expressão do movimento nas fotografias de guerra e as técnicas do "ligeiramente fora de foco" utilizadas por Robert Capa (SERVA, 2020, p.73). Também nessa parte, possível perceber a importância dos estudos que o autor empreendeu no Instituto Warburg.

Em seguida, o segundo painel é composto por imagens relacionadas ao medo e terror que se desenvolvem diante da ameaça de morte. Avançando na mesma orientação, o painel 3 tem como foco o tema das emoções explicitadas nos rostos, já que os movimentos faciais revelam de maneira clara e imediata aquilo que é sentido e, neste caso, sentimentos como o desespero, tristeza e dor.

Ao colocar o motivo dos decapitados, no painel de número 4, o autor explora o sentido dessas imagens a partir de personagens conhecidos no imaginário ocidental, como na narrativa de Sansão e Dalila ou de Perseu e a cabeça da Medusa. Outro exemplo bastante conhecido na iconografia ocidental, Davi e Golias, na gravura de Gustav Doré ou na pintura de Caravaggio, a imagem da cabeça do gigante degolado retrata a vitória do herói bíblico. Em muitas fotografias de guerra, a imagem de decapitados é utilizada para amedrontar, aterrorizar e também para expor a brutalidade dos grupos que cometem esses atos.

Imediatamente associadas à morte, as caveiras são o foco do painel 5. Na reflexão de Serva, as caveiras são vistas como signos para tratar a questão 
da pós-vida e seu impacto social. No painel 6 , imagens que orbitam em torno do motivo da crucificação exibem cenas bíblicas ao lado das fotografias de guerra, com pessoas enforcadas. As imagens evocam a atrocidade dessas práticas que levam à morte por asfixia. Em seu texto sobre este painel, Serva propõe uma reflexão sobre o tema a partir de Jung que vê, tanto na crucificação como no enforcamento, a imagem de corpos pendurados. Logo em seguida, no grupo que compõe o painel 7 , temos uma série de imagens que evocam o tema da descida da cruz, do sacrifício realizado e remetem à figura de Cristo e do mártir já morto.

O tema das pessoas vivas em chamas reúne as imagens do painel 8. Com forte evocação no imaginário ocidental, essas imagens provocam o choque por meio da expressão do sofrimento explícito e apontam para figuras dos mártires incendiados como Joana d'Arc. No painel 9, em que o motivo é o massacre dos inocentes, as imagens concentram temas como sofrimento e desespero e despertam empatia e compaixão. Em algumas dessas cenas, as crianças aparecem sozinhas, com ausência da expressão de dor de suas mães, mas, mesmo assim, são imagens extremamente impactantes. O painel de número 10, o último conjunto, tem os fuzilados como tema aglutinador. Serva inicia a discussão sobre esse grupo falando sobre uma capa da revista Esquire de 1967 que apresenta a imagem de Muhammad Ali com seu corpo repleto de flechadas. A imagem faz referência a São Sebastião, um mártir da Igreja Católica. Também foram reunidas outras duas imagens desse santo e uma pintura de Goya. Presentes no imaginário em cenas como heróis condenados, os corpos dos fuzilados surgem em imagens que indicam uma gestualidade de torção.

\section{Os processo de criação}

Ao resgatar conceitos de Warburg, Serva (2020) desenvolve um exercício crítico e criativo sobre as imagens de guerra que não apenas se utiliza do método warburguiano expresso em fórmulas de pathos, mas também anuncia as bases de um processo de análise de imagens extremamente original. Conforme apontamos no início deste texto, os painéis podem ser compreendidos como instrumentos na produção de conhecimento, quer seja no exercício combinatório de aproximação de imagens como também na descoberta de padrões expressivos e, assim, uma das grandes virtudes do livro de Serva é justamente contribuir para o desenvolvimento de pesquisas em processos de criação na comunicação e na cultura. Sobre este aspecto, 
à guisa de esclarecimento, estamos nos referindo à uma abordagem teórica e prática, que compreende a criação como rede em contínua construção semiótica, gerando sistemas dinâmicos de significação e complexidade. Nesta vertente investigativa, uma das grandes questões é justamente indagar a respeito dos materiais e métodos, visto que os fenômenos a serem estudados exigem a adoção de abordagens sistêmicas e abertas (LEÃO; SALLES, 2011).

Em suas considerações finais, Serva comenta como foi o processo de busca pelas fórmulas da emoção por parte do repórter fotográfico, tanto no momento do clique quanto na seleção das fotografias a serem publicadas, revelando que o processo criativo é afetado por tais fórmulas, ultrapassando a ideia ingênua que considera a fotografia como registro fiel da realidade. Segundo o autor, a fotografia de guerra estabelece uma maneira peculiar de propagar as fórmulas da emoção, ecoando gestualidades e potências universais que constituem a tradição iconográfica da humanidade. Das fórmulas de emoção definidas pelos fotógrafos no momento do enquadramento e registro das fotos, aos processos de pós-produção, seleção, edição e publicação, as Pathosformeln acionam processos de reconhecimento de gestos, expressões e imagens.

Traçando um paralelo entre o método investigativo empregado por Serva e o princípio da cartografia (DELEUZE, GUATTARI, 1995, p. 32-33), podemos observar alguns pontos de contato. Os painéis, compreendidos como dispositivos de experimentação, possibilitam inúmeras combinações e descobertas, apontando para procedimentos típicos da cartografia, tal como foi pensada pela dupla de pensadores franceses, e desenvolvida por outros autores para o estudo do imaginário. Segundo essa abordagem, o ato de cartografar requer um pensamento do tipo rizomático:

[...] um pensamento em fluxo, sempre em processo, múltiplo e heterogêneo. Da mesma maneira, os processos de mapeamento estão ligados a um pensamento de multiplicidade, permanente devir, e assim, o ato de cartografar é um gesto definitivamente inacabado. Enquanto sistema acentrado, não-hierárquico e nãosignificante, o rizoma projetaconstantemente novas e múltiplas conexões. (LEÃO, 2020).

Em suma, entre as várias virtudes do presente livro, Serva - ao adotar o uso dos painéis de Warburg na busca de uma rede relacional entre as imagens e ao propor 10 fórmulas da emoção para o exame das imagens de guerra 
- nos oferece também uma valiosa e singular contribuição para os estudos em processos de criação, do imaginário e da cultura.

Lucia Leão é coordenadora e professora do Programa de Pós Graduação em Comunicação e Semiótica da PUC-SP, líder do grupo de pesquisa em Comunicação e Criação nas Mídias InterLab21-CCM, CNPq da PUC-SP. É Pós Doutora pela UNICAMP, mestre e doutora em Comunicação e Semiótica, bacharel em Artes e especialista em Ação Cultural (ECA-USP). Seus interesses de pesquisa incluem: comunicação e semiótica, processos de criação, hipermídia, cibercultura e educação, teoria da imagem e imaginário, fotografia, audiovisual, arte e tecnologia.

lucleao@pucsp.br

Luma Santos de Oliveira é aluna do doutorado em Comunicação e Semiótica pela PUC-SP. Realizou graduação em Artes Visuais e mestrado na Universidade Federal de Mato Grosso do Sul. É membro do grupo de pesquisa Comunicação e Criação nas Mídias, InterLab21-CCM, CNPq da PUC-SP. Tem experiência na área de Artes, com ênfase em Fotografia, atuando principalmente nos seguintes temas: processos de criação, comunicação e cultura, fotografia, tecnologia, arte contemporânea e semiótica.

lumaluma@gmail.com

Contribuições de cada autor: Lucia Leão - supervisão, fundamentação teórica, metodologia, revisão e edição do texto; Luma Oliveira - primeira redação.

\section{Referências}

BAITELLO, N. A serpente, a maçã e o holograma. esboços para uma teoria da mídia. São Paulo: Paulus, 2010.

DARWIN, C. A expressão das emoções no homem e nos animais. São Paulo: Companhia das Letras, 2013.

DELEUZE, G; GUATTARI, F. Mil platôs: capitalismo e esquizofrenia. São Paulo: Editora 34, v. 1, 1995. 
DIDI-HUBERMAN, G. Atlas ou o gaio saber inquieto - O olho da história, III. Belo Horizonte: Editora UFMG, 2018.

GINZBURG, C. "De A. Warburg a E. H. Gombrich: Notas sobre um problema de método". Mitos, emblemas, sinais: morfologia e história. São Paulo: Companhia das Letras, 1999.

GOMBRICH, E. H. Aby Warburg: una biografía intelectual. Madri: Alianza Editorial, 1992.

KNIGHTLEY, P. The first casualty: The War Correspondent as Hero and Myth-maker from the Crimea to Iraq. London: Andre Deutsch, 2003.

LEÃO, L. Pensar o método e a produção de conhecimento. V!RUS, São Carlos, n. 20, 2020. [online]. Disponível em: <http://www.nomads.usp.br/virus/virus20/?sec=4\&item=2\&lang=pt>. Acesso em: 12 Abr. 2021.

LEÃO, L; SALLES, C. A pesquisa em processos de criação: três perspectivas. In: $20^{\circ}$ Encontro Nacional da Anpap: Subjetividade, utopias e fabulações. Rio de Janeiro. p. 3865-3879, 2011.

SERVA, L. A fórmula da emoção na fotografia de guerra. São Paulo: Edições Sesc São Paulo, 2020.

WARBURG, A. A renovação da antiguidade pagã. Rio de Janeiro: Contexto, 2013.

WARBURG, A. "Dürer e a antiguidade italiana". In: Histórias de fantasmas para gente grande: escritos, esboços e conferências. São Paulo: Companhia das Letras, 2015.

Resenha recebida em 02/04/2021 e aprovada em 05/05/2021. 